\title{
Pharmacological correction of technological stress in bulls and assessment of the influence of stress factors on semen quality
}

\author{
Anastasiia Chaplynskikh, ${ }^{1, *}$, and Ivan Nikulin ${ }^{1}$ \\ ${ }^{1}$ Voronezh State Agrarian University named after Emperor Peter the Great, Michurina street 1, Voronezh city, 394087, Russian \\ Federation
}

\begin{abstract}
The current conditions for the intensification of animal husbandry dictate a significant increase in the physiological and functional load on the body of productive animals, resulting in a failure of adaptive capacity, which manifest themselves in the violation of reproduction function and the development of pathological states. Research by domestic and foreign scientists has shown that stress plays a leading role in the etiology and pathogenesis of diseases leading to a reduction in animal reproduction $[3,4,9]$. Although the topic of stress is often covered in the scientific literature, some of its features are not fully explored. This is particularly true for male producers whose genetic material has a direct impact on livestock productivity and livestock production $[1,3,4,11]$. Therefore, the study of the influence of stress factors on the reproductive capacity of males and their pharmaco-rectification is relevant. The aim of our research was to assess the degree of influence of technological stress factors on the reproduction function of the bull producers and to develop a pharmaco-correction scheme to prevent stress effects on sperm quality. In relation to the objective, the following objectives were proposed:

1. Study the reaction of the ox producers to the effects of technological stress;

2. Determine the influence of drugs Amber biostimulator, Azoxyvet on the quality of bull sperm.

Keywords: bulls, cattle, Aberdeen-angus, sperm, «Azoxyvet», «Amber biostimulator», stress.
\end{abstract}

\section{Introduction}

No progress can be made in livestock production without the proper organization of animal reproduction [4]. Reproduction is an important biological process, which is a major component of profitable meat husbandry [11]. At present «BMK» have annual losses due to the loss of calves, infertility and strength of animals, low percentage of fruitful insemination of repair chicks, low quality of sperm of ox-producers. Technological stress is the sum of the stress factors accompanying the technology: hypodynamy, tissue hypoxia, dense planting, frequent movement, etc. [9.11]. The greatest disturbances in the animal are observed when the sum of several stress factors is applied to the animal. The effects of these stress factors result in metabolic disorders, reduced reproductive capacity, reduced productivity and reduced economic exploitation, resulting in economic loss of production [10]. The search for a solution to the problem of reproduction is ongoing. At the same time, the problem of determining the mechanisms for determining the effectiveness of insemination is most pressing. In our view, the pharmacological correction of technological stresses arising from the breeding of cattle of the Aberdeen-Angus breed is of key importance [5]. One of the priority areas in the prevention of technological stress is the creation or search for formulations with pronounced antioxidant effects for use in integrated therapy $[3,6,12]$. Research on the impact of vitamin supplements, adaptogens, immunomodulators and succinic acid preparations with a preventive purpose for stress correction has been the subject of research by a number of researchers [3.4.5.6.8.12].

\section{Materials and methods}

The work was completed in 2020 at Farm Krasny Yar «BMK» in the period from April to June. The research focused on Aberdeen-Angus bulls aged 22-24 months weighing $650-700 \mathrm{~kg}$. Three groups of bulls were formed with 50 heads each. The control group underwent a procedure of testing the seeds used in the farm without any pharmacological means of correcting technological stress. The experimental group 1 was injected with Azoxivet intramuscularly at a dose of 0.1 $\mathrm{mg} / \mathrm{kg}$ twice at 14-day intervals, the experimental group 2 was injected with Amber Biostimulator intramuscularly at a dose of $10 \mathrm{ml}$ twice at 14-day intervals, Two injections were made seven days before the supposed sperm quality assessment. At the time of the studies, the bulls of all groups were under the same feeding and housing conditions. The contents were outdoor, in special pens, enclosed by pipes, feeding twice full of mixed rations (silage, hay, straw, corn spit, premix mineral), water production from wells. Fresh semen samples were taken during the planned testing of

\footnotetext{
Corresponding author: chapik95@mail.ru
} 
bulls for product quality by means of a transrectal electrostimulant. The quality of the sperm was evaluated by microscopy (microscope MICROMEDE): the general type of ejaculate, mobility, morphology and sperm concentration were evaluated, and the circumference of the scrotum and the state of the mouth were assessed visually. The following methods were used to examine the samples:

- quality assessment of sperm by appearance;

- microscopic examination of sperm for sperm activity in $\%$;

- determination of the sperm concentration in the Goryaev chamber;

- morphology was determined by the number of sperm with a straight forward motion and the number of sperm with a pathological movement in $\%$.

The degree of influence of stress factors on the clinical status of bulls was assessed according to the following criteria: temperature, pulse, respiration, appetite, motor activity, salivation, number of cutbacks of scar, number of chewing movements. The influence of technological stress on exchange processes in animals was evaluated on the basis of the total protein, urea and amine nitrogen content, also estimated testosterone and cholesterol content on the basis of the FGB of the Central Laboratory for Research and Development of the Tula Test Laboratory. Blood was taken from 15 bulls, 5 in each group from the tail vein twice, before exposure to technological stress and at the moment of exposure to technological stress, during the taking of semen.

\section{Results and discussions}

Following the impact of technological stress factors, changes in the clinical status of bull producers were observed. The body temperature of the control group increased by 3.1 per cent compared to the background, heart rate decreased by 7.4 per cent, respiratory rate increased by 46.1 per cent, appetite decreased in 60 of 150 bulls, 35 showed uncertain movements, 40 showed aggressions, Salivation was increased in 88 individuals, the number of chewing movements decreased by $7.8 \%$, the number of cutbacks after feeding by $28.5 \%$. Based on the data, it can be concluded that Azoxyvet and Amber biostimulator drugs influence the organism of the bull producers before taking sperm. The body temperature of the experimental group 1 was $2.0 \%$ lower than that of the control group 2 by $1.5 \%$, heart rate decreased by $1.3 \%$ and $2.7 \%$; respiratory rate decreased by $21.0 \%$ and $26 \%$; appetite decreased by 30 and 10 bulls; the number of chewing movements was 1.07 and 3.1 per cent; number of cuts of scar after feeding by 33.0 and 20.0 per cent.

Table 1. Evaluation of the sperm quality of Aberdeen-Angus $(\mathrm{n}=150)$

\begin{tabular}{|c|c|c|c|}
\hline Group & $\begin{array}{c}\text { Mobility, } \\
\%\end{array}$ & $\begin{array}{c}\text { Morphology, } \\
\%\end{array}$ & Concentration \\
\hline Control & $52,4 \pm 1,2$ & 70,0 & 0,77 \\
\hline $\begin{array}{c}\text { Experiment } \\
1\end{array}$ & $68,0 \pm 1,6$ & 70,0 & 0,89 \\
\hline
\end{tabular}

\begin{tabular}{|c|c|c|c|}
\hline $\begin{array}{c}\text { Experiment } \\
2\end{array}$ & $67,7 \pm 0,8$ & 70,0 & 0,88 \\
\hline
\end{tabular}

Based on the data presented in Table 1, the sperm mobility of Experimental Group 1 was $13 \%$ higher than that of background 2 by $13.0 \%$. In an assessment of morphology, 7 bulls with pathological sperm (with defects in the cervix and head) were identified A general pattern in groups after the use of drugs and without pharmacological correction of technological stress has not been identified. There was no significant impact on the estimation of the prostate and the circumference of the scrotum. It can be concluded that the average sperm concentration of the ejaculate-producing bulls of Aberdeen-Angus group 1 using Azoxyvet was 0,89 billion/ml, experimental group 2 with application of Amber biostimulator 0.88 billion $/ \mathrm{ml}$. This increased by $13.5 \%$ and $12.5 \%$ compared to control $(0.77$ billion $/ \mathrm{ml})$.

Table 2. Blood metabolism of bull producers $(n=15)$

\begin{tabular}{|c|c|c|}
\hline \multirow{2}{*}{ Group } & $\begin{array}{c}\text { Interval of time of blood draws } \\
\text { Before the } \\
\text { impact of } \\
\text { technological } \\
\text { stress }\end{array}$ & $\begin{array}{c}\text { At the time of } \\
\text { ejaculate }\end{array}$ \\
\hline \multicolumn{3}{|c|}{ Common protein, g/l } \\
\hline Control & $78,20 \pm 0,59$ & $73,82 \pm 0,22$ \\
\hline Experiment 1 & $75,00 \pm 0,91$ & $71,71 \pm 0,01$ \\
\hline Experiment 2 & $75,02 \pm 0,06$ & $73,40 \pm 0,33$ \\
\hline \multicolumn{3}{|c|}{ Urea, mmol/1 } \\
\hline Control & $3,99 \pm 0,10$ & $6,99 \pm 0,33$ \\
\hline Experiment 1 & $4,41 \pm 0,09$ & $5,84 \pm 0,42$ \\
\hline Experiment 2 & $4,31 \pm 0,12$ & $6,01 \pm 0,25$ \\
\hline \multicolumn{3}{|c|}{ Amine nitrogen, mmol/1 } \\
\hline Control & $4,55 \pm 0,03$ & $10,24 \pm 0,88$ \\
\hline Experiment 1 & $4,53 \pm 0,08$ & $8,90 \pm 0,19$ \\
\hline Experiment 2 & $4,61 \pm 0,01$ & $9,01 \pm 0,41$ \\
\hline
\end{tabular}

Technological stress did not significantly affect the total protein content in the blood, with only a slight decrease in the control group by 5.6\%; an experimental 1 by $4.1 \%$; and an experimental 2 by $2.1 \%$. The increased glucocotrticoid function of the adrenal cortex on protein exchange, due to technological stress factors, has contributed to the increase of urea and amine nitrogen in the blood of experimental animals: The concentration of urea increased by $42.9 \%$ in the control group; by $24.5 \%$ in the experimental 1 ; by $28.2 \%$. Similar to the change in the concentration of urea, the concentration of amine nitrogen in animals changed. In the control group, $55.5 \%$; in the experimental group, 1 by $49.1 \%$; in the experimental group, 2 by $48.8 \%$.

Table 3. Blood indicators of the hormonal status of bull producers $(n=15)$

\begin{tabular}{|c|c|c|}
\hline \multirow{2}{*}{ Group } & \multicolumn{2}{|c|}{ Interval of time of blood draws } \\
\cline { 2 - 3 } & $\begin{array}{c}\text { Before the } \\
\text { impact of } \\
\text { stress-factor }\end{array}$ & $\begin{array}{c}\text { At the time of } \\
\text { ejaculate }\end{array}$ \\
\hline
\end{tabular}




\begin{tabular}{|c|c|c|}
\hline \multicolumn{3}{|c|}{ Testosterone, $\mathrm{mmol} / \mathrm{l}$} \\
\hline Control & $17,84 \pm 0,29$ & $14,04 \pm 0,12$ \\
\hline Experiment 1 & $17,50 \pm 0,91$ & $16,71 \pm 0,21$ \\
\hline Experiment 2 & $17,92 \pm 0,06$ & $16,40 \pm 0,20$ \\
\hline \multicolumn{3}{|c|}{ Cholesterol, mmol/1 } \\
\hline Control & $2,39 \pm 0,20$ & $3,99 \pm 0,13$ \\
\hline Experiment 1 & $2,41 \pm 0,19$ & $3,04 \pm 0,49$ \\
\hline Experiment 2 & $2,31 \pm 0,22$ & $3,01 \pm 0,25$ \\
\hline
\end{tabular}

According to table 3, it was found that technological stress affects the serum content of testosterone and cholesterol: in the control group testosterone decreased by $21.3 \%$; experimental 1 by $4.5 \%$; experimental 2 by $8.4 \%$; cholesterol increased by $40 \%, 1 \% ; 20.7 \% ; 23.2 \%$.

\section{Conclusion}

Based on the data obtained, it can be noted that the use of Azoxyvet and Amber biostimulator affects the quality of sperm produced by bull producers:

- The movement of the sperm of Experimental Group 1 was $13 \%$ higher than the background; the mobility of Experimental Group 2 was $13.0 \%$;

- Sperm concentrations in ejaculate of bull producers in Test Group 1 increased by 13.5 and $12.5 \%$ in Test Group 2 compared to control $(0.77$ billion $/ \mathrm{ml})$.

The use of these drugs reduces the adverse effect of stress factors on the clinical status of bull producers and protein exchange: the body temperature of the experimental group 1 was lower by $2.0 \%$ compared to control, the experimental group 2 by $1.5 \%$ and the heart rate by 1.3 and 2.7 per cent; respiratory frequency 21.0 and 26 per cent; appetite reduced in 30 and 10 bulls; number of chewing movements increased by 1.7 and 3.1 per cent; number of scarring reductions after feeding by 33.0 and 20.0 per cent.

The concentration of urea in Experimental 1 was $18.4 \%$ lower than in the control group; in Experimental Group 2, 14.7\%. The amine nitrogen content in the animal blood in Experimental Group 1 was $6.4 \%$ lower than in the background; in Experimental Group 2, it was $6.7 \%$.

The serum testosterone content in Test Group 1 was $16.8 \%$ higher than that of Test Group 1; Test Group 2 was $12.9 \%$; Cholesterol content was $19.4 \%$ lower than that of Test Group 1; and Test Group 2 was $16.9 \%$.

Thus, it is possible to recommend preparations «Azoxyvet» and «Amber biostimulator» for pharmacocorrection of technological stress in bulls-producers.

\section{References}

1. G.M. Andreev, V.U. Davydov Top. Prob. of vet. Med.: sb. Criterion of evaluation of fertilisation potentials of cattle-sperm producers 124 (2015)

2. B. A. Bagirov, V. P. Kononov, B. A. Yochliev. Agriculto biol. Fertility of sperm and chromatin status: control methods (overview) 23 (2012)

3. V. P. Burkat, L. A. Begma, N. I. Ivanchenko Cur. prob. of animal reprod. boil.: materials of the Int..
Nauc-Prakt. cong. VIJ (25-26 Oct. 2007) Increased sperm production of Echinacea purple 263 (2007)

4. A. M. Guskov Zootechnia Influence of stress factors on the reproductive function of animals 422 (Moscow, 2007)

5. G. V. Yeshchen, N. A. Kombarova, R. A. Kornilin Prob. of boil. of prod. animals. Spec. is. Stabilization of sperm production in young bull producers during the period of long thermal stress with the aid of the preparation «Bakshin-vet» 440 (2011)

6. A.A. Ivanov, T.M. Bulynina, D.M. Utina, A.V. Odintsov, A.Y. Bushmanov Notes by the DS A U 8 67 (2014)

7. V. Kalashnikov, V. Levakhin Dairy and meat herding Some problems of meat herding development and ways of solving them 12 (Moscow, 2006)

8. E. A. Korochkina, K. V. Nephew Vet. Health. Reproduction capacity of males under stress 73840 (2013)

9. V.I. Levakhin et al. Stress and methods of stress correction in agricultural animals 161 (Moscow, 2008)

10. V.G. Semyonov, F.P. Petryankin, D.A. Nikitin, A.B. Volkov Sci.-educ. Environ. as a bas. of develop. of agro-ind. comp. and soc. infrastructure of the village: mat. Int. H.M. Prakt. Konf. Commemorate the 85th anniversary of the FGBU VB Chuvash GSHA Mechanisms of action of stress-factors of different forces on internal environment of animal 317 (Cheboksary, 2016)

11. S. Tikhonov, N. Tikhonova, A. Monastery Mol. Cattle breed. Stress prevention problem in cattle breeding 3132006

12. L.V. Khalturina All-Rus. Nauch. Vet. Research. in-t. pathology, pharm. and therapy Reproductive potential of oxen-producers in conditions of the Ural region and ways of increasing it : thesis ... candidate of veterinary sciences 164 (Yekaterinburg, 2013)

13. V.V. Khramtsov, I.E. Grigorieva, V.Y. Nikitin et al. Obstetrics and gynaecology of agricultural animals (Koloss, Moscow,2008)

14. B.J. Hayes, H.A. Lewin, M.E. Goddard Review Art. Trends in Gen. The future of livestock breeding: genomic selection for efficiency, reduced emissions intensity, and adaptation 294206 (2013)

15. N. L. Selokar, P. Sharma, M. Saini, S. Sheoran, R. Rajendran, D. Kumar, P. S Yadav Sci. Reports. Successful cloning of a superior buffalo bull. 9(1) (2019)

16. S.Vince et al. Animal Age-related differences of semen quality, seminal plasma, and spermatozoa antioxidative and oxidative stress variables in bulls during cold and warm periods of the year 12559 2018

17. M.J. Morrell, Theriogenology Heat stress and bull fertility 15362 (2020)

18. C. C. Murphy et al. J. Dairy Sci. Reducing sperm concentration is critical to limiting the oxidative stress challenge in liquid bull semen 964447 (2018) 